\title{
TIME-RESOLVED REGRESSION RATE OF INNOVATIVE HYBRID SOLID FUEL FORMULATIONS
}

\author{
C. Paravan, A. Reina, A. Sossi, M. Manzoni, \\ G. Massini, G. Rambaldi, E. Duranti, A. Adami, \\ E. Seletti, and L. T. DeLuca
}

Space Propulsion Laboratory, Aerospace Engineering Dept. Politecnico di Milano 34 via La Masa, Milan 20156, Italy

Low regression rates limit application of hybrid rocket engines (HREs). In this paper, combustion of HTPB- and solid paraffin wax-based fuels is investigated in a lab-scale burner by a time-resolved optical technique. The effects of pressure are explored over the range 7 to 16 bar. Nanosized (ALEX ${ }^{\mathrm{TM}}, 100 \mathrm{~nm}$, uncoated) and micronsized (MgB composite, $5 \mu \mathrm{m})$ metal additives are tested. For all runs, the instantaneous regression rate is not constant but higher at the beginning of tests. Overall, $\mathrm{MgB}$ performance and relatively ease of manufacturing enable to consider this additive as an interesting novel candidate to enhance hybrid rocket engines performance.

\section{NOMENCLATURE}

$\bar{A}$

$\langle A\rangle$

$2 \mathrm{D}$

$a$

$a_{s}$ ALEX $^{\mathrm{TM}}$

AP

BET

$\mathrm{CCP}$

$D$

$D_{i}$

DMA space-averaged value (of parameter $A$ )

time-averaged value (of parameter $A$ ) two-dimensional multiplicative factor [Eqs. (1) and (5)] mean surface particle diameter, $\mathrm{nm}$

ALuminum EXploded Ammonium Perchlorate Brunauer-Emmet-Teller Condensed Combustion Product port diameter, $\mathrm{mm}$ $i$ th sampled port diameter, $\mathrm{mm}$

Dynamic Mechanical Analysis 
DOA DiOctyl-Adipate

DSC Differential Scanning Calorimetry

EEW Electrical Explosion of Wire

fps frames per second

$G \quad$ mass flux, $\mathrm{kg} /\left(\mathrm{m}^{2} \cdot \mathrm{s}\right)$

GOx Gaseous Oxygen

$H \quad$ specific enthalpy, $\mathrm{J} / \mathrm{g}$

HRE Hybrid Rocket Engine

HTPB Hydroxyl-Terminated PolyButadiene

IPDI IsoPhorone DiIsocyanate

$\dot{m}$ mass flow rate, $\mathrm{kg} / \mathrm{s}$

$n$ power law exponent [Eqs. (1) and (5)]

$\mathrm{nAl}$ nanosized Aluminum

nlpm normal-liter per minute

$\mathrm{O} / \mathrm{F} \quad$ Oxidizer-to-Fuel ratio

$p_{c} \quad$ chamber pressure, bar

$R^{2} \quad$ correlation index

$r_{f} \quad$ solid fuel regression rate, $\mathrm{mm} / \mathrm{s}$

$S_{\mathrm{sp}} \quad$ specific surface, $\mathrm{m}^{2} / \mathrm{g}$

SW Solid paraffin Wax

$t$ time, $\mathrm{s}$

$t_{\text {ign }} \quad$ ignition time, $\mathrm{s}$

$T$ Temperature, ${ }^{\circ} \mathrm{C}$

TG ThermoGravimetry Analysis

TOT Thickness Over Time

\section{Greek Symbols}

$\alpha \quad$ transformation degree, $\%$

$\Delta \quad$ difference

$\Delta t_{\text {ign }}$ ignition delay, $\mathrm{s}$

$\rho \quad$ solid fuel density, $\mathrm{g} / \mathrm{cm}^{3}$

$\sigma \quad$ standard deviation

\section{Subscripts}

0 reference condition

APS Air PaSsivated

conv convective

$D$ diameter [Eq. (1)]

$f \quad$ fuel

fin final

$h$ horizontal 


$\begin{array}{ll}i & i \text { th sampled value } \\ \text { ign } & \text { ignition } \\ \text { onset } & \text { oxidation onset } \\ \text { Ox } & \text { Oxidizer } \\ r & \text { regression rate }[\text { Eq. }(5)] \\ s & \text { surface } \\ v & \text { vertical }\end{array}$

\section{Superscripts}

0 pure material

\section{INTRODUCTION}

Thermochemical propulsion is the leading technology for access to space and inspace propulsion. Solid rocket motors and liquid rocket engines are mature systems serving in several applications. Nevertheless, the former lacks operational flexibility and, when using AP as oxidizer, produces highly pollutant exhausts, whereas the latter, though highly performing, is characterized by complex design and operations $[1,2]$. Hybrid rocket engines offer high theoretical performance, flexibility, and reliability while enabling possible costs savings due to safe grain manufacturing/handling/transport with respect to solid propulsion and simpler operations with respect to liquid propulsion [3]. Therefore, hybrid systems could satisfy new requirements from access to space market (as improvement of the present launch systems performance or private access to space needs), in-space navigation, and de-orbiting of decommissioned spacecrafts. The main drawbacks of HREs are the low regression rate of the solid fuel and the poor combustion efficiency. These drawbacks hinder the possible advantages coming from the exploitation of hybrid systems and are related to the diffusive nature of the HRE flame $[1,2]$. Focus of this paper is on the regression rate enhancement of HREs by loading the solid fuel grain with energetic fillers; additional analyses will be needed for combustion efficiency.

\section{Literature Survey}

In HREs, the oxidizer and the fuel are stored in different states of matter. In the most common configuration, the oxidizer is fluid (liquid or gaseous) while the fuel is solid. The fluid oxidizer flows toward the solid fuel grain generating a boundary layer. After ignition, the gasified fuel diffuses into the oxidizer flow. Where the $\mathrm{O} / \mathrm{F}$ reaches the flammability limits of the considered mixture, a flame is established within the boundary layer. Fundamentals of this 
phenomenon were investigated by Marxman et al. [4-6]. In their model, the regression rate of solid grain was identified as a strong function of the total mass flux resulting from the oxidizer stream $G_{\mathrm{Ox}}$ and the fuel $G_{f}$ gasified from the regressing surface: $r_{f} \propto G^{0.8}$ [4]. Under the investigated conditions, a coupling between convective and radiation heat transfer was identified but the proposed model was not accurate enough to consider a pressure dependence of regression rate for $p_{c}<10$ bar (reducing $r_{f}$ for decreasing pressure). Marxman and coworkers addressed this effect to chemical kinetics and possible radiation heat-transfer influences on regression rate.

Further investigations on hybrid combustion were conducted by Smoot and Price [7]. A dependence of the regression rate on $G_{\mathrm{Ox}}$, as well as on pressure for $p_{c}<12$ bar was identified in their work. The former resulted in a powerlaw relationship reflecting the one proposed by Marxman and coworkers, while heterogeneous surface reactions were identified as possible source for the pressure dependence. A recent comprehensive discussion about pressure influence on $r_{f}$ in hybrid systems is reported in [8].

In past studies, regression rate was usually evaluated by spatially and temporally averaging procedures based on TOT measurement techniques [8-10]. In recent studies conducted at Pennsylvania State University, instantaneous regression rate measurement by X-rays radiography leads to $r_{f} \propto G^{0.6}$ for tests on HTPB burning in gaseous oxygen [10].

In order to overcome the intrinsic low regression rate limitations affecting HRE, several techniques have been proposed [2, 8, 11-15]. The use of paraffinbased formulations producing entrainment of melted fuel droplets was originally proposed by Karabeyoglu et al. [16, 17]. Though high performing in terms of regression rate enhancement, entrainment-producing fuels such as solid paraffins exhibit poor mechanical properties that are incompatible with large-scale applications [18].

Metal additives used for solid fuel loading include micronsized and nanosized powders of metals or metal hydrides [15]. With micronsized particles, the regression rate increase is mainly due to enhanced radiation heat- transfer from the flame zone to the fuel grain surface [14]. Nanosized powders provide lower $T_{\text {ign }}$ (higher reactivity) than micronsized counterpart due to their high specific surface $\left(\sim 10 \mathrm{~m}^{2} / \mathrm{g}\right.$ vs. $\sim 0.1 \mathrm{~m}^{2} / \mathrm{g}$ of micronsized particles). The ignition delay of nanosized particles is, therefore, shortened and this, in turn, yields energy release closer to the vaporization surface. Because of this, nanosized particles can result highly effective in enhancing $r_{f}$ [14]. Nanosized powders require a proper dispersion technique during manufacturing in order to counteract the particles tendency to cluster causing a reduction of their effective $S_{\mathrm{sp}}$ [14]. Aluminum is an attractive energetic additive for solid fuel loading. Under DTA/TG testing conditions as well as rocket engine burning conditions, $\mathrm{nAl}$ exhibits high reactivity related to the high $S_{\mathrm{sp}}$ due to its small particle size. The ignition of $\mathrm{nAl}$ takes place at temperatures close to the melting temperature of aluminum while 
micronsized Al ignites at temperatures close to the melting point of alumina [1921]. Due to this high reactivity yielding higher combustion efficiency, $\mathrm{nAl}$ could result more effective than micronsized additives in ballistic performance enhancement.

SPLab of Politecnico di Milano has developed several test rigs and diagnostic techniques to investigate hybrid combustion $[22,23]$. In particular, a timeresolved technique for regression rate measurement has been developed [23]. The aim of SPLab experimental activity is to identify a solid-fuel formulation with high enough regression rate as well as a suitable set of properties for industrial, large-scale applications (performance, mechanical properties, safety, and costs).

\section{TESTED FORMULATIONS AND INGREDIENTS}

The baseline formulation is HTPB-R45 plasticized by DOA, cured with IPDI (curing level $-\mathrm{NCO} /-\mathrm{OH}=1.04$ ) with dibutyltin diacetate as curing catalyst. The manufacturing is carried out in a controlled atmosphere vessel with a constant temperature of $60{ }^{\circ} \mathrm{C}$ to improve miscibility and to reduce gaseous inclusions by lessening HTPB viscosity. The detailed composition of HTPB binder is indicated in Table 1. Data for the reference SW-based fuel formulation are reported in Table 2 .

Table 1 The HTPB fuel formulation and ingredients density

\begin{tabular}{lcc}
\hline \multicolumn{1}{c}{$\begin{array}{c}\text { Component } \\
\text { (short hand notation) }\end{array}$} & $\begin{array}{c}\text { Mass fraction, } \\
\text { \% wrt. fuel mass }\end{array}$ & $\begin{array}{c}\text { Density, } \\
\mathrm{kg} / \mathrm{m}^{3}\end{array}$ \\
\hline Hydroxyl-terminated polybutadiene (HTPB-R45) & 79.0 & 901 \\
Dioctyl adipate (DOA) & 13.1 & 920 \\
Isophorone diisocyanate (IPDI) & 7.67 & 1061 \\
Dibutyltin diacetate (TIN) & 0.23 & 1321 \\
\hline HTPB binder & 100 & $\sim 920$ \\
\hline
\end{tabular}

${ }^{*}$ Pyrolysis of cured HTPB extensively discussed in [24, 25].

Table 2 The SW fuel formulation and ingredients density

\begin{tabular}{lcr}
\hline \multicolumn{1}{c}{ Component } & $\begin{array}{c}\text { Mass fraction, } \\
\text { (short hand notation) }\end{array}$ & $\begin{array}{c}\text { Density, } \\
\mathrm{kg} / \mathrm{m}^{3}\end{array}$ \\
\hline Solid prt. fuel mass & 88.0 & 890 \\
Stearic acid & 10.0 & 845 \\
Carbon & 2.0 & 2100 \\
SW binder & 100 & $\sim 900$ \\
\hline
\end{tabular}

${ }^{*}$ Melting temperature $57-59^{\circ} \mathrm{C}$. 


\subsection{Characteristics of Energetic Additives}

Two different metal additives are considered in this work. The first one is $\mathrm{ALEX}^{\mathrm{TM}}$, a $\mathrm{nAl}$ with nominal size of $100 \mathrm{~nm}$ produced by EEW, passivated by slow, dry air stream after production (APS) and uncoated. The reactivity parameters and physical characteristics of the ALEX ${ }^{\mathrm{TM}}$ powder, defined according to [26-28], are reported in Table 3 and in Fig. 1.

The second tested energetic additive is MgB90 (20\% Mg). This innovative micronsized additive is a composite metal powder binding boron with $90 \%-92 \%$ purity (B90) to magnesium ( $\mathrm{Mg}$ mass fraction of $20 \%$ with respect to particle total mass). MgB powder is characterized by a mass-weighted mean diameter of $5.2 \mu \mathrm{m}$ and by $S_{\mathrm{sp}}$ of $\sim 3.5 \mathrm{~m}^{2} / \mathrm{g}$ (as evaluated by Malvern Mastersizer 2000, see Fig. 2). Boron offers a very high volumetric heat of oxidation, but it is characterized by difficult ignition and poor combustion efficiency [14]. The $\mathrm{MgB}$

Table $3 S_{\mathrm{sp}}$ (evaluated by nitrogen absorption, BET) and active $\mathrm{Al}$ content for investigated $\mathrm{nAl}$ powder

\begin{tabular}{lccc}
\hline Additive & $S_{s p}, \mathrm{~m}^{2} / \mathrm{g}$ & $a_{s}, \mathrm{~nm}^{a}$ & $\mathrm{Al}^{0}$ content, $\%^{b}$ \\
\hline $\mathrm{ALEX}$ & 11.8 & 202 & 89 \\
\hline $\begin{array}{l}{ }^{a} a_{s}=6 /\left(S_{\mathrm{sp}} \rho_{\mathrm{Al}}\right) . \\
{ }^{b} \text { Evaluated by volumetric method after } \\
\text { evolution. }\end{array}$
\end{tabular}

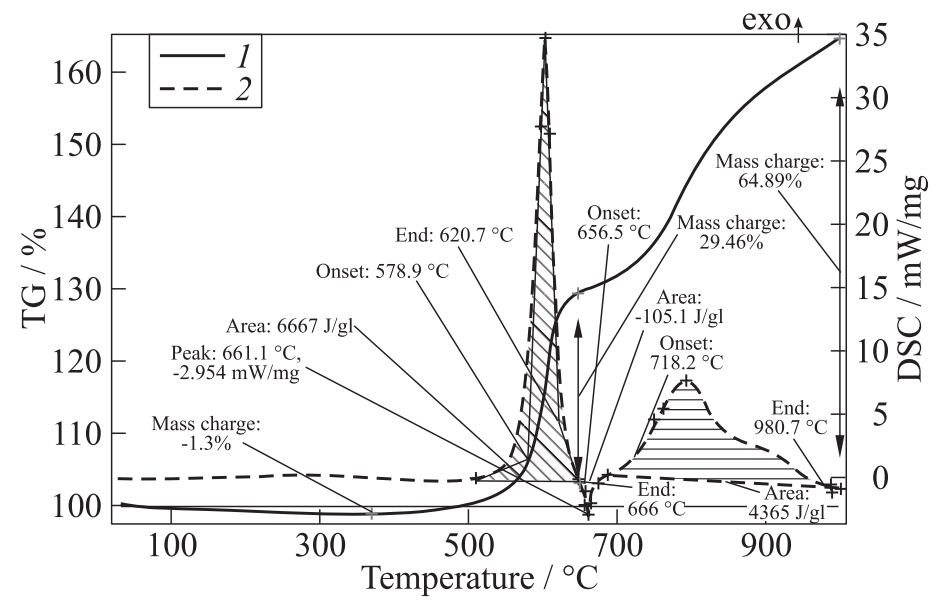

Figure 1 The TG (1) and DSC (2) of ALEX ${ }^{\mathrm{TM}}$ tested under air with heating rate of $10{ }^{\circ} \mathrm{C} / \mathrm{min}$ (reference sample $\left.\alpha-\mathrm{Al}_{2} \mathrm{O}_{3}\right)$. Note first oxidation peak $\left(603.5{ }^{\circ} \mathrm{C}\right.$, $34.71 \mathrm{~mW} / \mathrm{mg})$ prior aluminum melting and second $\left(793^{\circ} \mathrm{C}, 7.668 \mathrm{~mW} / \mathrm{mg}\right)$ less intense phase of oxidation (2), both oxidation phases are related to a mass gain (1) 


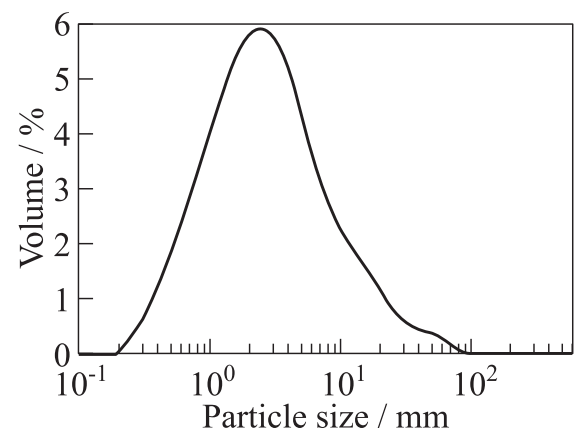

Figure 2 Particle size distribution of $\mathrm{MgB} 90(20 \% \mathrm{Mg})$ as evaluated by Malvern Masetrsizer 2000
Table 4 Ignition temperature of the examined metal additives as measured under conductive heating in quiescent air at $1 \mathrm{bar}$, heating rate $\sim 300{ }^{\circ} \mathrm{C} / \mathrm{s}[29] ; T_{\text {ign }}$ of $\mathrm{MgB}$ decreases with respect to Boron (B90) for increasing $\mathrm{Mg}$ content

\begin{tabular}{lc}
\hline Metal powder & $T_{\text {ign }},{ }^{\circ} \mathrm{C}$ \\
\hline ALEX & $592 \pm 15$ \\
B90 & $731 \pm 31$ \\
MgB90 $(15 \% \mathrm{Mg})$ & $676 \pm 40$ \\
MgB90 $(20 \% \mathrm{Mg})$ & $654 \pm 57$ \\
\hline
\end{tabular}

powder is designed with the aim of lessening boron burning difficulties, thus making possible to exploit its energetic potential. Table 4 reports data on the $T_{\text {ign }}$ of the considered metal additives. ALEX ${ }^{\mathrm{TM}}$ exhibits the lowest ignition temperature of the tested additives. This is related to the small particle size yielding to enhanced reactivity due to the high $S_{\mathrm{sp}}$. In this respect, the ignition data reported in Table 4 confirm for ALEX ${ }^{\mathrm{TM}}$ the thermal response information from the DSC/TG testing reported in Fig. 1 (see the first oxidation peak). Considering the $\mathrm{MgB}$ data, magnesium acts lessening the ignition temperature of the additive when compared to the one of pure boron (B90).

\subsection{Energetic Additive Dispersion}

Exploiting the possible performance enhancements achievable by nanosized additives requires a proper dispersion of the energetic filler into the binder matrix down to the nanoscale. Particle cohesion phenomena during storage/ manufacturing yield the formation of large particle clusters instead of the desired nanosized powders. Moreover, $\mathrm{nAl}$ powders produced by EEW are subjected to sintering due to wire explosion during the production phase [30]. Dedicated studies are under progress at SPLab in order to lessen/avoid these phenomena by implementing proper dispersion techniques.

In the present work, two sessions of sonication were performed during manufacturing to avoid particle clustering and enhance dispersion of $\mathrm{nAl}$ in the binder matrix. An ultrasonic bath operating at a frequency of $37 \mathrm{kHz}$ was used. In the first phase, the required amount of $\mathrm{nAl}$ powder was mixed with nanosized carbon and then sonicated for $15 \mathrm{~min}$. After the addition of $\mathrm{nAl}$ and carbon to the binder, the required amount of DOA was added to the compound. After mixing, 


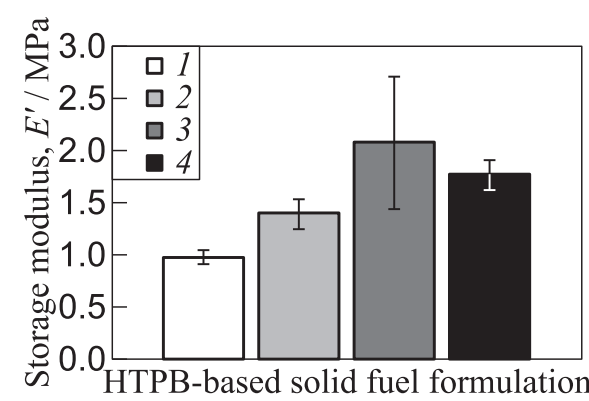

(a)

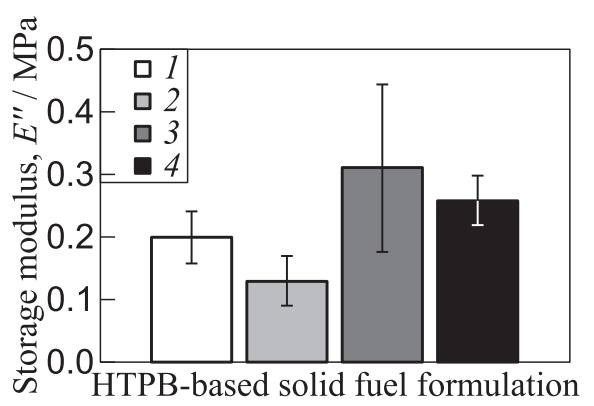

(b)

Figure 3 ALEX ${ }^{\mathrm{TM}}$-loaded fuels tested by DMA, storage $(a)$ and loss $(b)$ moduli. Sonicated fuel exhibits reduced data scattering under the investigated conditions (furnace temperature $40{ }^{\circ} \mathrm{C}$, oscillation frequency $10 \mathrm{~Hz}$, oscillation amplitude $15 \mu \mathrm{m}$ ): 1 - HTPB; 2 - HTPB $+2 \%$ C ; $3-\mathrm{HTPB}+2 \% \mathrm{C}+10 \%$ ALEX (not sonicated); and $4-\mathrm{HTPB}+2 \% \mathrm{C}+10 \%$ ALEX (sonicated)

the whole fuel formulation was sonicated for $15 \mathrm{~min}$ more. The effects of sonication were evaluated by mechanical tests conducted on the manufactured fuel by DMA. Cured HTPB (see Table 1) is taken as the reference formulation. HTPB loaded with $2 \% \mathrm{C}$ is considered to evaluate the $\mathrm{C}$ effects on solid fuel mechanical properties. Then two different nAl-loaded fuels were investigated. Both of them contain $10 \%$ mass fraction of $\mathrm{ALEX}^{\mathrm{TM}}$ and $2 \%$ of $\mathrm{C}$, but they differ from the sonication phase. The first nAl-loaded fuel was treated in the ultrasonic bath as previously stated, while in the second formulation, fillers were added without any sonication treatment.

The results achieved by DMA tests are reported in Fig. 3. Under the investigated conditions, sonication of fuel formulation enables a reduction in the data scattering of DMA measurements. The result is common for the storage as well as for the loss modulus. The first one is associated with the elastic behavior of the filled polymeric fuel, while the second one accounts for the viscous component. This reduction in the measured properties scattering is attributed to an improved additive dispersion, since clusters in the solid fuel grains are responsible for nonhomogeneous mechanical properties [31].

\section{EXPERIMENTAL SETUP AND REGRESSION RATE MEASUREMENT}

The experimental testing was conducted in a $2 \mathrm{D}$ radial microburner [22, 23]. This facility enables burning of cylindrical-shape samples with a single central 
port perforation (initial nominal diameter of $4 \mathrm{~mm}$ ) under controlled chamber pressure and oxidizer mass flow. A digital flow-meter placed on the oxidizer inlet provides real-time control of the oxidizer mass flow rate, while the servoactuators placed on the gas exhaust dump line grant a quasi-steady chamber pressure. The tested strand is connected to an injector delivering the oxidizer flow. A secondary (nitrogen) flow cools and cleans the internal parts of the facility. Ignition of the tested samples is achieved by a pyrotechnic primer charge. The latter is inserted in the sample port, at the head-end side, and is ignited by a laser beam impinging on it. Each combustion run is visualized and recorded by a digital camera, working in the range from 25 to $1000 \mathrm{fps}$ depending on the operating conditions. An optical time-resolved technique is used to analyze the solid fuel regression and is based on diameter sampling in time [23]. The sample head-end is visible during the test allowing $D_{i}$ measurement along different radial directions from each of the recorded combustion images (with a sampling frequency $\sim 10 \mathrm{~Hz}$ ). By averaging these values, the instantaneous diameter characterizing the considered frame, $\bar{D}_{i}$, is obtained. The sequence of the sampled space-averaged diameters so collected constitutes a discrete information in time, which can be successively interpolated to achieve a continuous evolution $\bar{D}(t)$, see Eq. (1).

To circumvent the difficulties of the ignition transient, the function describing the diameter evolution in time is valid only starting from $t_{\text {ign }}$ [23]. This parameter is defined ad-hoc as the one maximizing the data fitting of Eq. (1), when associated to the first sampled diameter of the considered sequence of data. The ad-hoc defined $t_{\text {ign }}$ is compared to the corresponding ignition delay $\left(\Delta t_{\text {ign }}\right)$ estimated under the hypothesis of ignition due to exclusive convective heat transfer [32]. An overview of the results achieved with ad-hoc defined $t_{\text {ign }}$ is reported in Table 5. According to the discussed procedure, the behavior of the solid fuel central port during combustion can be defined as

$$
\bar{D}(t)-D_{0}=a_{D}\left(t-t_{0}\right)^{n_{D}}, \quad t \geq t_{\text {ign }}>t_{0} .
$$

Table 5 Convective ignition delay $\left(\Delta t_{\text {ign,conv }}[32,33]\right)$ and ad-hoc evaluated $\Delta t_{\text {ign }}$ showing a general agreement for increasing $p_{c}$. Fuel - HTPB. The relatively large difference at 7 bar is likely due to irregular primer charge ignition

\begin{tabular}{cccc}
\hline Pressure, bar & $\begin{array}{c}G_{\text {Ox }}\left(\bar{D}_{\text {ign }}\right), \\
\mathrm{kg} /\left(\mathrm{m}^{2} \cdot \mathrm{s}\right)\end{array}$ & $\Delta t_{\text {ign,conv }}=t_{\text {ign,conv }}-t_{0}$, & $\Delta t_{\text {ign }}=t_{\text {ign }}-t_{0}$, \\
$\mathrm{s}$ & $\mathrm{s}$ \\
\hline 7 & 357.3 & 0.023 & 0.070 \\
10 & 381.2 & 0.021 & 0.021 \\
13 & 357.4 & 0.020 & 0.059 \\
16 & 384.0 & 0.019 & 0.023 \\
\hline
\end{tabular}


All results achieved by the time-resolved technique are checked by comparing the corresponding TOT data to assess the consistency between different data reduction techniques:

$$
\begin{aligned}
& r_{f}\left(t_{\mathrm{ign}}\right)=\frac{1}{2} a_{D} n_{D}\left(t_{\mathrm{ign}}-t_{0}\right)^{n_{D}-1} \stackrel{?}{=} \frac{n_{D}}{2} \frac{\bar{D}\left(t_{\mathrm{ign}}\right)-D_{0}}{t_{\mathrm{ign}}-t_{0}} \\
&\left\langle r_{f}\left(t_{\mathrm{fin}}\right)\right\rangle=\frac{1}{t_{\mathrm{fin}}-t_{\mathrm{ign}}} \int_{t_{\mathrm{ign}}}^{t_{\mathrm{fin}}} r_{f}(t) d t \stackrel{?}{=} \frac{1}{2} \frac{\bar{D}\left(t_{\mathrm{fin}}\right)-\bar{D}\left(t_{\mathrm{ign}}\right)}{t_{\mathrm{fin}}-t_{\mathrm{ign}}} ; \\
&\left\langle G_{\mathrm{Ox}}\left(t_{\mathrm{fin}}\right)\right\rangle=\frac{1}{t_{\mathrm{fin}}-t_{\mathrm{ign}}} \int_{t_{\mathrm{ign}}}^{t_{\mathrm{fin}}} G_{\mathrm{Ox}}(t) d t \\
& \stackrel{?}{=} \frac{\dot{m}_{\mathrm{Ox}}}{(\pi / 4)\left\{\left[\bar{D}\left(t_{\mathrm{ign}}\right)+\bar{D}\left(t_{\mathrm{fin}}\right)\right] / 2\right\}^{2}} .
\end{aligned}
$$

For each test, the relevant parameters of Eq. (1), $a_{D}$ and $n_{D}$, are thus defined. However, data scattering is often observed due to the essentially turbulent diffusion nature of the flame. For a given formulation, the various $\bar{D}(t)$ so obtained are collapsed into an ensemble-average curve, of the same kind of Eq. (1), including all of the performed tests. In addition, to make easier comparisons with literature data, a power-law approximation of $r_{f}$ vs. $G_{\mathrm{Ox}}$ is proposed, for each test as well as for the ensemble curves, as

$$
r_{f}\left(G_{\mathrm{Ox}}\right)=a_{r} G_{\mathrm{Ox}}(t)^{n_{r}}, \quad t \geq t_{\mathrm{ign}}>t_{0} .
$$

The data achieved by application of Eqs. (1) and (5) to ensemble curves enable definition of proper error bars, defined in $t$ and $G_{\mathrm{Ox}}$ domains, respectively, for Eqs. (1) and (5). In order to evaluate the error bars for a given ensemble, a proper time (or $G_{\mathrm{Ox}}$ ) range is evaluated considering the limits where the curves of all the performed single tests are defined. Over this latter interval, the error bars are evaluated by confidence intervals centered on the average value resulting from single test diameters at a given time [for Eq. (1)] or regression rates at a given $G_{\mathrm{Ox}}$ [for Eq. (5)]. Confidence intervals are evaluated with 95 percent accuracy.

\section{RESULTS AND DISCUSSIONS}

Burning of all tested formulations is investigated under GOx, with oxidizer volumetric flow rate of $210 \mathrm{nlpm}$ [corresponding to an initial nominal $G_{\text {Ox }}$ of $\left.\sim 400 \mathrm{~kg} /\left(\mathrm{m}^{2} \cdot \mathrm{s}\right)\right]$, while the chamber pressure ranges from 7 to $16 \mathrm{bar}$. 


\subsection{HTPB Fuel}

In order to illustrate the time-resolved technique step-by-step, the results for the ballistic characterization of HTPB tested at 10 bar are reported in Figs. 4 [diameter change in time, Eq. (1)] and $5\left(r_{f}\right.$ vs. $\left.G_{\text {Ox }}\right)$. Table 6 shows the obtained data for $a_{D}$ and $n_{D}$ as well as the power-law approximation $r_{f}$ vs. $G_{\mathrm{Ox}}$ for each single test and also the deduced ensemble average; results for consistency checks are reported in Table 7 . Considering Fig. 4, the strand central port diameter exhibits a monotonic increase in time during burning. In turn, this behavior yields the monotonic decrease of $r_{f}$ for decreasing $G_{\mathrm{Ox}}$ illustrated in Fig. $5 a$. Under the investigated conditions, HTPB regression rate for high oxidizer mass fluxes is characterized by a marked difference with respect to the power-law approximation commonly accepted for convective heat transfer regimes [4] (see Fig. $5 b)$.

Table 8 and Fig. 6 show the data for HTPB burning under four values of $p_{c}$. The data reported in Fig. 6 exhibit no significant influence of $p_{c}$ on $r_{f}$ and rather point out a substantial overlapping of the confidence intervals in the range $100<G_{\text {Ox }}<300 \mathrm{~kg} /\left(\mathrm{m}^{2} \cdot \mathrm{s}\right)$.

Under the investigated operating conditions, the regression rate of the HTPB baseline can be summarized by a power-law approximating function taking into account both $G_{\mathrm{Ox}}$ and $p_{c}$ effects as

$$
r_{f}\left(G_{\mathrm{Ox}}, p_{c}\right)=(0.035 \pm 0.001) G_{\mathrm{Ox}}^{0.566 \pm 0.001} p_{c}^{-0.005 \pm 0.002} ; \quad R^{2}=0.870 .
$$

In spite of the low quality of the data fitting, Eq. (6) underlines the substantial lack of dependency of pure HTPB regression rate on pressure under the investigated conditions. On the other hand, the regression rate sensitivity to the

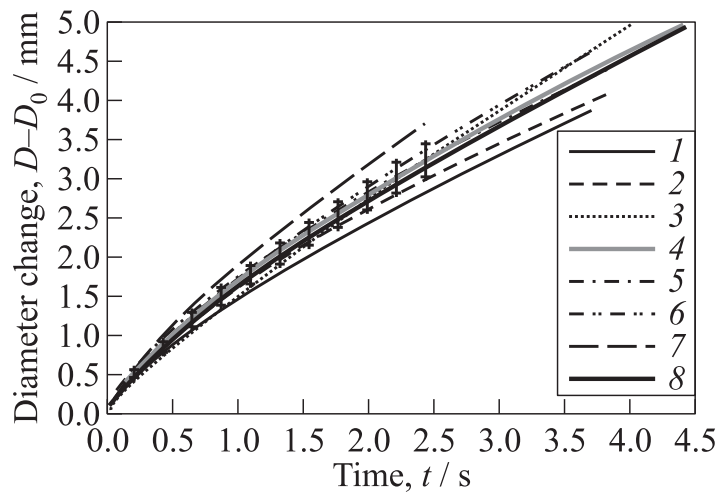

Figure 4 HTPB burning in GOx at 10 bar: diameter change in time for the single tests and the ensemble average: $1-7$ - tests from No. 01 to No. 07 ; and 8 - ensemble 


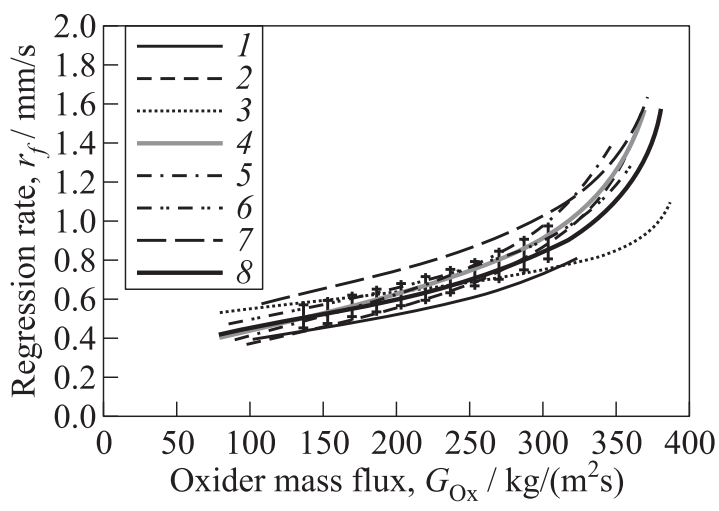

(a)

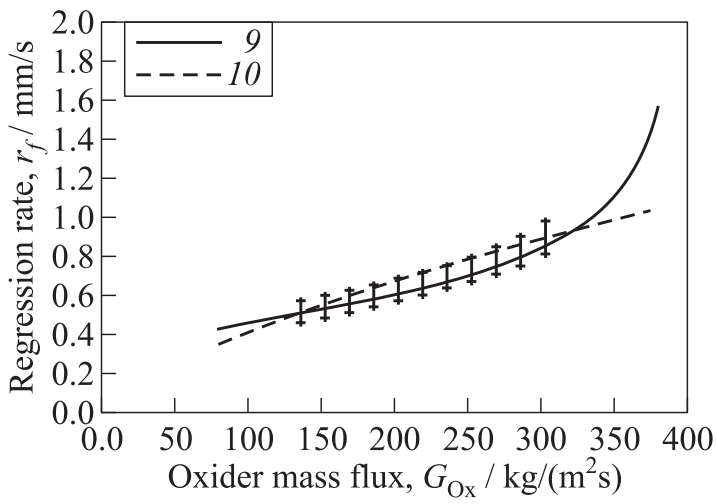

(b)

Figure 5 HTPB burning in GOx at 10 bar: $(a) r_{f}$ vs. $G_{\text {Ox }}$ for the single tests $(1-7)$ and the ensemble average $(8)$, and $(b)$ the ensemble average with the power-law approximation of Eq. (5) (9- ensemble; and 10 - ensemble, power-law approximation)

oxidizer mass flux is below the 0.8 value identified by diffusion-limited theories in the convective regime. For HTPB/GOx, this holds true for all investigated operating conditions as testified by the results presented in Table 8 and Eq. (6). The observed low values of $n_{r}$ can be related to radiation heat transfer and fragmentation effects of the solid fuel grain [34]. In fact, toward the end of the combustion process (low $G_{\text {Ox }}$ ), fuel fragments are seen to detach from the fuel grain (Figs. 7 and 8). Fragmentation enhances regression rate with respect to solid fuel gasification driven by the heat feedback from the flame zone to the regressing surface. Under the investigated conditions, solid fuel grain fragmentation occurs more and more as pressure increases. Under these circumstances, if the experimental data of diameter evolution in time for $G_{\mathrm{Ox}}<120 \mathrm{~kg} /\left(\mathrm{m}^{2} \cdot \mathrm{s}\right)$ 
Table 6 HTPB burning under GOx at 10 bar: ballistic parameters for Eqs. (1) and (5). Low quality of the data fitting for $r_{f}$ vs. $G_{\text {Ox }}$ approximation testifies the poor agreement between the power-law approximation and the actual data (see Fig. 5)

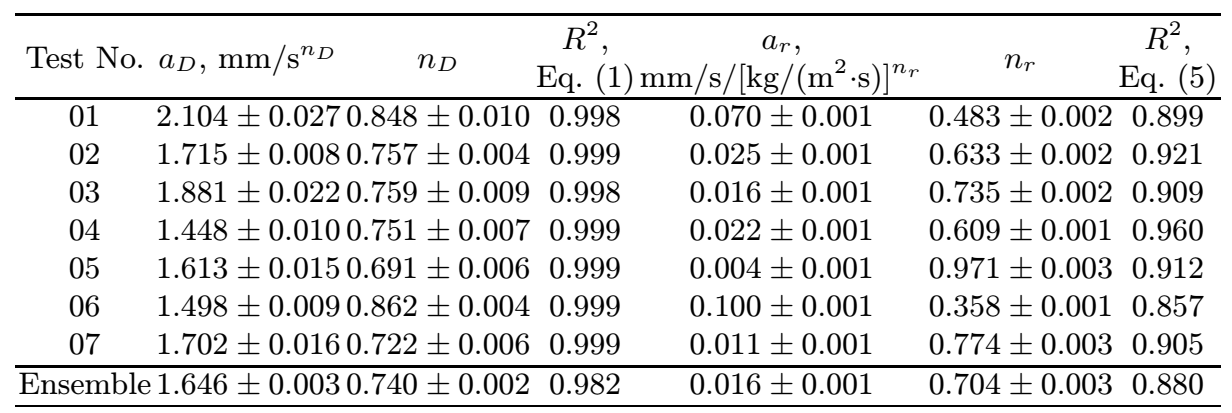

Table 7 HTPB burning under GOx at 10 bar: data consistency checks according to Eqs. (2)-(4). Differences between data reduction techniques are due to solid fuel grain fragmentation and other effects of hybrid burning

\begin{tabular}{cccc}
\hline Test No. & Eq. $(2), \%^{a}$ & Eq. $(3), \%^{a}$ & Eq. $(4), \%^{a}$ \\
\hline 01 & 0.1 & 0.2 & -2.2 \\
02 & -0.1 & 1.8 & -0.4 \\
03 & -0.2 & -1.9 & -8.1 \\
04 & 0.1 & 0.3 & -2.4 \\
05 & 0.1 & 0.6 & -0.4 \\
06 & 0.5 & -1.0 & -3.0 \\
07 & 1.0 & -0.7 & -1.1 \\
\hline
\end{tabular}

${ }^{a}$ Percentage evaluated with respect to TOT values.

Table 8 HTPB burning under GOx at different $p_{c}$ : instantaneous ensemble average curves for $r_{f}$ vs. $G_{\mathrm{Ox}}$ in the power-law approximation of Eq. (5). Note low values of $n_{r}$ and poor values of the data fitting quality

\begin{tabular}{cccc}
\hline Pressure, bar & $a_{r}, \mathrm{~mm} / \mathrm{s} /\left[\mathrm{kg} /\left(\mathrm{m}^{2} \cdot \mathrm{s}\right)\right]^{n_{r}}$ & $n_{r}$ & $R^{2}$, Eq. $(5)$ \\
\hline 7 & $0.046 \pm 0.001$ & $0.516 \pm 0.002$ & 0.914 \\
10 & $0.016 \pm 0.001$ & $0.704 \pm 0.003$ & 0.880 \\
13 & $0.025 \pm 0.001$ & $0.638 \pm 0.002$ & 0.919 \\
16 & $0.052 \pm 0.001$ & $0.489 \pm 0.002$ & 0.866 \\
\hline
\end{tabular}




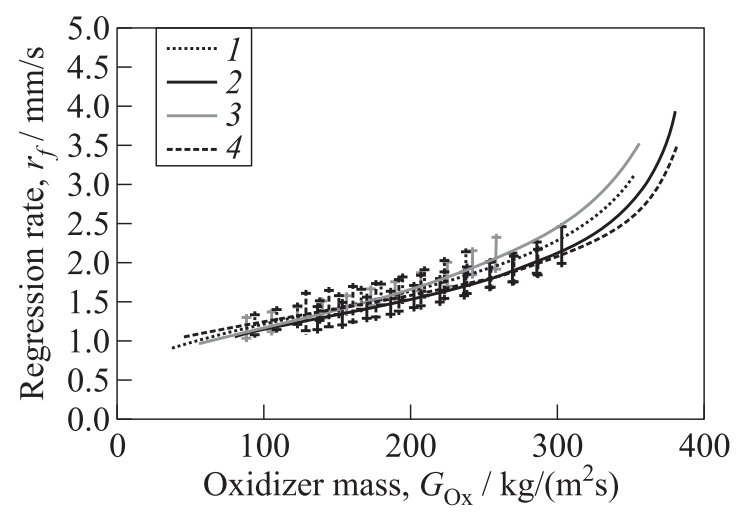

Figure 6 HTPB burning in GOx at different $p_{c}$ : instantaneous ensemble averages curves for $r_{f}$ vs. $G_{\mathrm{Ox}}$ showing no significant pressure influence on $r_{f}: 1-7$ bar; $2-$ 10 ; $3-13$; and $4-16$ bar

are removed, higher values of $n_{r}$ are achieved as shown in Table 9. This exclusion does not otherwise modify the general trend of the experimental data reported in Fig. 5, as testified by Eq. (7) now replacing Eq. (6).

$$
r_{f}\left(G_{\mathrm{Ox}}, p_{c}\right)=(0.011 \pm 0.001) G_{\mathrm{Ox}}^{0.786 \pm 0.001} p_{c}^{0.019 \pm 0.001} ; \quad R^{2}=0.885 .
$$

\subsection{Wax Fuel}

Pressure effects were investigated also for the SW-based formulations burning in GOx in the pressure range 7 to 16 bar (Fig. 9). In spite of the data scattering observed especially at 7 bar, SW exhibits regression rates up to 5 times higher than HTPB under similar operating conditions. The resulting $r_{f}$ vs. $G_{\mathrm{Ox}}$ of the power-law approximation was found quite close to the available literature data, as shown in Table 10 [16, 17]. Testing conducted at 13 bar is characterized by high quality of the data fitting of the $r_{f}$ vs. $G_{\mathrm{Ox}}$ in the power-law approximation. This is likely due to the low $G_{\mathrm{Ox}}$ induced by a relatively large diameter measured at ignition. As a matter of fact, the poor mechanical properties of SW may cause elevated diameter consumptions at ignition and, thus, combustion starts from a relatively low oxidizer mass flux with respect to the nominal value. As a consequence, the experimental data do not exhibit a definite shift from the standard power-law approximation.

The following equation enables to evaluate the pressure effect on $r_{f}$ for the SW fuel and, under the tested operating conditions, this shows up to be slightly negative:

$$
r_{f}\left(G_{\mathrm{Ox}}, p_{c}\right)=(0.056 \pm 0.001) G_{\mathrm{Ox}}^{0.889 \pm 0.002} p_{c}^{-0.393 \pm 0.002} ; \quad R^{2}=0.918 .
$$




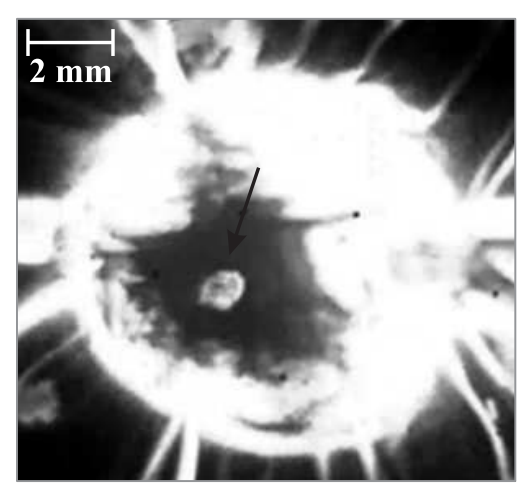

(a)

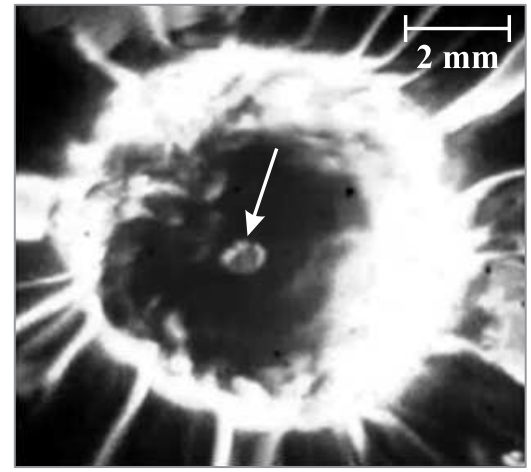

(b)

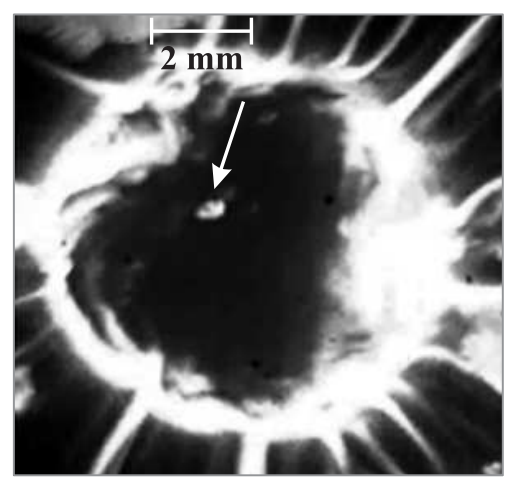

(c)

Figure 7 HTPB burning in GOx at 16 bar: CCPs detaching from the regressing surface as pointed out by the arrows: $(a) t_{\text {ign }}+2.638 \mathrm{~s} ;(b) t_{\text {ign }}+2.642 \mathrm{~s}$; and $(c) t_{\text {ign }}$ $+2.646 \mathrm{~s}$

Even though more runs are required to properly investigate the phenomenon, it is possible that changes in chamber pressure alter the solid fuel melting and the entrainment phenomena.

\subsection{Metallized HTPB and Solid Paraffin Wax Fuels}

The data collected on HTPB- and SW-based fuels enable a relative grading of the regression rates achieved by the tested metallized formulations, under the same oxidizer mass flow rate of $210 \mathrm{nlpm}$, for a range of $p_{c}$. Pure HTPB was taken as a baseline. The metallized HTPB formulations differ because of different additive particle sizes and mass fractions. HTPB loaded with $2 \%$ Carbon 


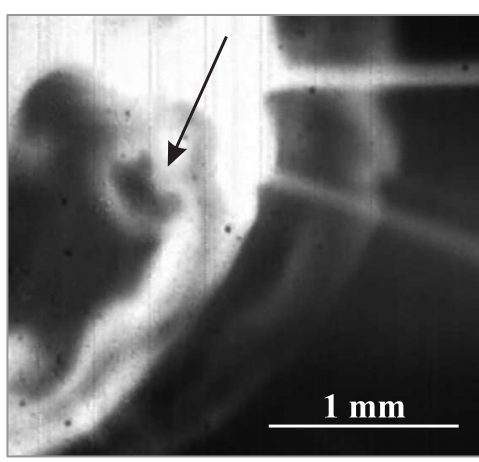

(a)

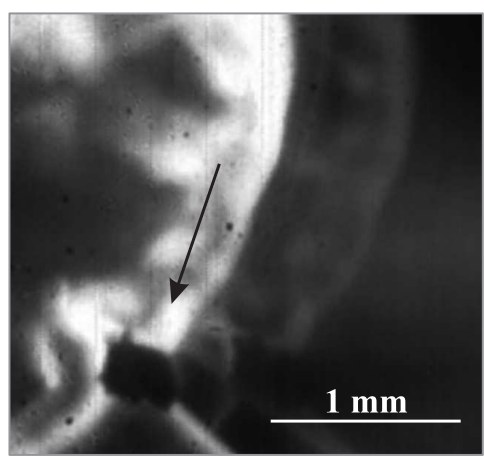

(c)

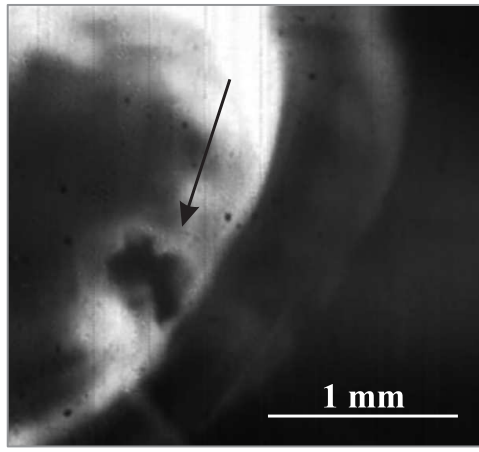

(b)

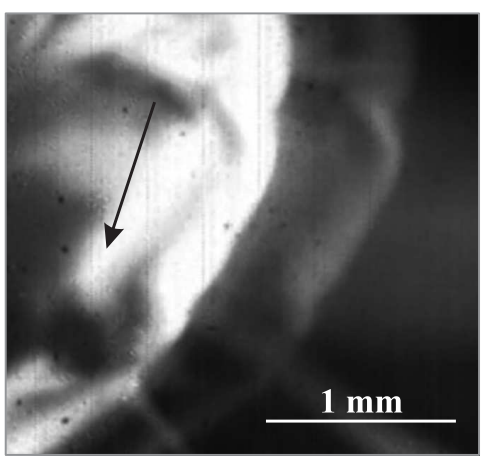

(d)

Figure 8 HTPB burning in GOx at 13 bar: close visualization of CCPs detaching from the regressing surface as pointed out by the arrows: $(a) t_{\text {ign }}+2.761 \mathrm{~s} ;(b) t_{\text {ign }}+2.769 \mathrm{~s}$; (c) $t_{\text {ign }}+2.771 \mathrm{~s} ;$ and $(d) t_{\text {ign }}+2.772 \mathrm{~s}$

Table 9 HTPB burning under GOx: instantaneous ensemble average curves of $r_{f}$ vs. $G_{\mathrm{Ox}}$ for $G_{\mathrm{Ox}}>120 \mathrm{~kg} /\left(\mathrm{m}^{2} \cdot \mathrm{s}\right)$

\begin{tabular}{cccc}
\hline Pressure, bar & $a_{r}, \mathrm{~mm} / \mathrm{s} /\left[\mathrm{kg} /\left(\mathrm{m}^{2} \cdot \mathrm{s}\right)\right]^{n_{r}}$ & $n_{r}$ & $R^{2}$, Eq. $(5)$ \\
\hline 7 & $0.012 \pm 0.001$ & $0.762 \pm 0.002$ & 0.938 \\
10 & $0.007 \pm 0.001$ & $0.856 \pm 0.003$ & 0.891 \\
13 & $0.007 \pm 0.001$ & $0.857 \pm 0.002$ & 0.937 \\
16 & $0.016 \pm 0.001$ & $0.705 \pm 0.003$ & 0.887 \\
\hline
\end{tabular}

and $10 \%$ ALEX $^{\mathrm{TM}}$ was tested at 10 bar while HTPB loaded with $2.8 \%$ MgB90 $(20 \% \mathrm{Mg})$ was tested at 13 bar. The additive mass fractions were tailored so that the MgB-loaded fuel contains half of the metal (Boron) moles than the ALEX $^{\mathrm{TM}}$-loaded fuel. 


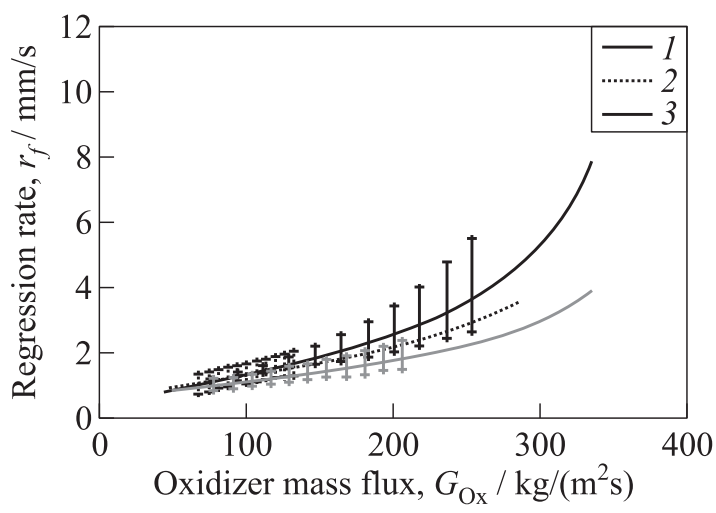

Figure 9 Solid paraffin wax burning in GOx in the pressure range from 7 to 16 bar ( $1-7$ bar; $2-13$; and $3-16$ bar): instantaneous ensemble averages curves for $r_{f}$ vs. $G_{\mathrm{Ox}}$. In spite of the data scattering, increasing $p_{c}$, a decrease in $r_{f}$ is perceivable

Table 10 Solid paraffin wax burning under GOx: instantaneous ensemble average curves of $r_{f}$ vs. $G_{\mathrm{Ox}}$. As for the HTPB-based formulation, the poor data fitting is due to ballistic response at high $G_{\mathrm{Ox}}$

\begin{tabular}{cccc}
\hline Pressure, bar & $a_{r}, \mathrm{~mm} / \mathrm{s} /\left[\mathrm{kg} /\left(\mathrm{m}^{2} \cdot \mathrm{s}\right)\right]^{n_{r}}$ & $n_{r}$ & $R^{2}$, Eq. (5) \\
\hline 7 & $0.010 \pm 0.001$ & $1.083 \pm 0.003$ & 0.936 \\
13 & $0.042 \pm 0.001$ & $0.765 \pm 0.001$ & 0.966 \\
16 & $0.029 \pm 0.001$ & $0.805 \pm 0.002$ & 0.939 \\
\hline
\end{tabular}

The regression rate response of HTPB loaded with ALEX $^{\mathrm{TM}}$ is illustrated in Fig. 10. Four tests were performed, but only the resulting ensemble curve is shown. The latter is characterized by $\Delta t_{\text {ign }}=0.006 \mathrm{~s}$, showing a reduced ignition delay compared to the corresponding baseline under the same operating conditions (see Table 5). This finding is in agreement with ALEX ${ }^{\mathrm{TM}}$ high reactivity as shown in Table 4 . HTPB loaded with ALEX ${ }^{\mathrm{TM}}$ features an impressive initial regression rate increase, accompanied by a strong sensitivity to $G_{\text {Ox }}$. As a consequence, the initial regression rate enhancement of $58 \%$ with respect to baseline at $380 \mathrm{~kg} /\left(\mathrm{m}^{2} \cdot \mathrm{s}\right)$ reduces to $48 \%$ at $370 \mathrm{~kg} /\left(\mathrm{m}^{2} \cdot \mathrm{s}\right)$ and vanishes for $G_{\mathrm{Ox}}<150 \mathrm{~kg} /\left(\mathrm{m}^{2} \cdot \mathrm{s}\right)$. Thus, the power law approximation of $r_{f}$ vs. $G_{\mathrm{Ox}}$ for HTPB loaded ALEX ${ }^{\mathrm{TM}}$ exhibits $n_{r}$ higher than the one of the baseline formulation (Table 11).

Under the investigated operating conditions, HTPB loaded with MgB90 $(20 \% \mathrm{Mg})$ exhibits a regression rate increase with respect to baseline of $48 \%$ over the entire $G_{\mathrm{Ox}}$ interval of testing as shown in Fig. 11. The dependence of $r_{f}$ from the oxidizer mass flux is weaker for $\mathrm{MgB}$ loading with respect to 


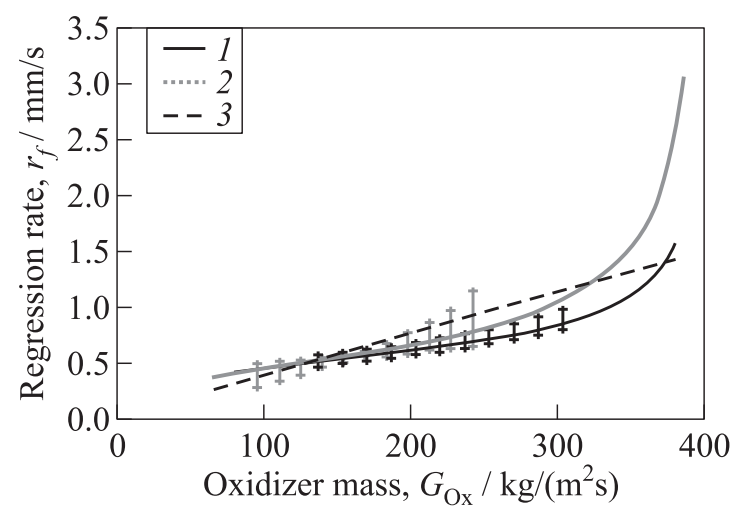

Figure 10 HTPB loaded with $2 \% \mathrm{C}$ and $10 \%$ ALEX $^{\mathrm{TM}}$ burning in GOx: instantaneous ensemble average curves for $r_{f}$ vs. $G_{\text {Ox }}$. Note the marked initial $r_{f}$ increase (time runs from right to left, maximum $G_{\mathrm{Ox}}$ is achieved at the beginning of the test) and high sensitivity to $G_{\mathrm{Ox}}: 1$ - baseline (HTPB); 2 - HTPB $+2 \% \mathrm{C}+10 \%$ ALEX $^{\mathrm{TM}}$; and $3-\mathrm{HTPB}+2 \% \mathrm{C}+10 \% \mathrm{ALEX}^{\mathrm{TM}}$, power-law approximation

Table 11 Power-law approximation (see Eq. (5)) of instantaneous $r_{f}$ vs. $G_{\text {Ox }}$ for the metallized fuels burning in GOx

\begin{tabular}{cccc}
\hline Solid fuel formulation & $\begin{array}{c}a_{r}, \\
\mathrm{~mm} / \mathrm{s} /\left[\mathrm{kg} /\left(\mathrm{m}^{2} \cdot \mathrm{s}\right)\right]^{n_{r}}\end{array}$ & $n_{r}$ & $\begin{array}{c}R^{2} \\
\text { Eq. }(5)\end{array}$ \\
\hline $\mathrm{HTPB}+2 \% \mathrm{C}+10 \% \mathrm{ALEX}{ }^{\mathrm{TM} a}$ & $0.005 \pm 0.001$ & $0.956 \pm 0.004$ & 0.854 \\
$\mathrm{HTPB}+2.8 \% \mathrm{MgB} 90(20 \% \mathrm{Mg})^{b}$ & $0.023 \pm 0.001$ & $0.724 \pm 0.002$ & 0.920 \\
$\mathrm{SW}+2.8 \% \mathrm{MgB} 90(20 \% \mathrm{Mg})^{b}$ & $0.003 \pm 0.001$ & $1.310 \pm 0.003$ & 0.942 \\
\hline
\end{tabular}

${ }^{a}$ Tested at 10 bar.

${ }^{b}$ Tested at 13 bar.

$\mathrm{ALEX}^{\mathrm{TM}}$, as it can be seen by comparing Figs. 10 and 11. HTPB loaded with MgB90 $(20 \% \mathrm{Mg})$ is characterized by $\Delta t_{\text {ign }}=0.038 \mathrm{~s}$, a value larger than HTPB loaded with ALEX ${ }^{\mathrm{TM}}$ but lower than the pure HTPB baseline (see Table 5). This is in agreement with the ignition temperatures as reported in Table 4.

This performance is achieved by a fuel formulation where the metal content is reduced in terms of both mass and molar fractions with respect to ALEX ${ }^{\mathrm{TM}}$ loaded HTPB. This means that further addition of MgB could enhance the ballistic response of the fuel. In addition, from the system performance viewpoint, this could also enable lower specific impulse losses due to the lower mass fraction of CCPs originated by the metal combustion. The MgB90 (20\% Mg) regression rate enhancement is likely due to the dual nature of the $\mathrm{MgB}$ powder: the Magnesium present in this metal composite makes viable its ignition at reduced 


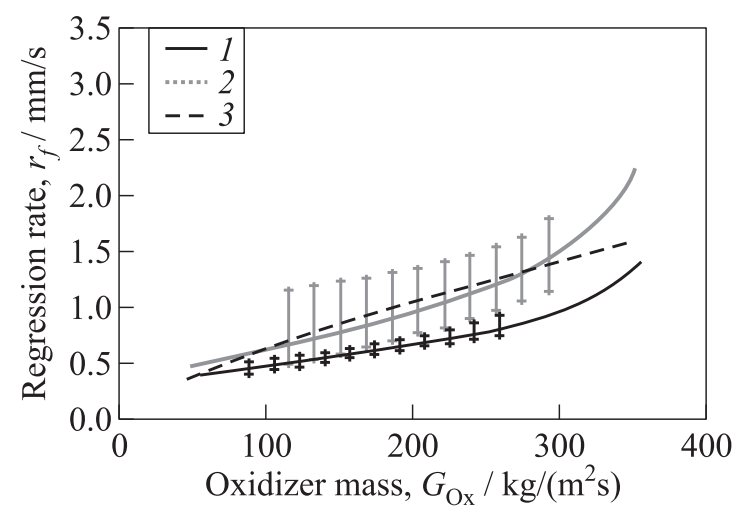

Figure 11 HTPB loaded with MgB90 (20\% Mg) burning in GOx: instantaneous ensemble average curve for $r_{f}$ vs. $G_{\mathrm{Ox}}$ with respect to HTPB baseline (1): $2-$ $\mathrm{HTPB}+2.8 \% \mathrm{MgB} 90$; and $3-\mathrm{HTPB}+2.8 \% \mathrm{MgB} 90$, power-law approximation

temperature/heat fluxes and, thus, helps in releasing the large combustion enthalpy of Boron

Owing to the relative ease of manufacturing and the reduced dispersion problem of micronsized additives with respect to nanosized ones, $\mathrm{MgB}$ was tested as an energetic additive also in SW-based fuels. Under high oxidizer mass fluxes, the MgB-loaded SW exhibits a significant regression rate increase with respect to both HTPB baseline and unloaded SW as shown in Fig. 12. Starting from an ox-

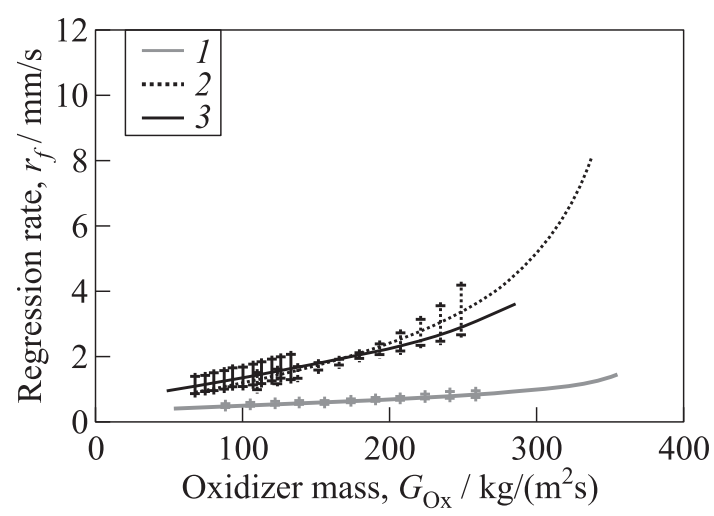

Figure 12 Instantaneous regression rates of SW-based fuels burning in GOx. With respect to HTPB baseline (1), under $G_{\mathrm{Ox}}=250 \mathrm{~kg} /\left(\mathrm{m}^{2} \cdot \mathrm{s}\right)$, regression rate increase is $322 \%$ for MgB-loaded SW (2 - SW $+2.8 \% \mathrm{MgB} 90(20 \% \mathrm{Mg})$ ) and $263 \%$ for unloaded SW (3) 
Table 12 Metallized HTPB- and SW-based fuels percent overall variations of $r_{f}$ and $m_{f}$ with respect to HTPB baseline, $\Delta$, and their standard deviation $\sigma_{\Delta}$. Higher $\sigma_{\Delta}$ implies higher sensitivity of the tested formulation to $G_{\text {Ox }}$ variation

\begin{tabular}{lrrrr}
\hline \multirow{2}{*}{ Solid fuel formulation } & \multicolumn{2}{c}{$r_{f}$} & \multicolumn{2}{c}{$m_{f}$} \\
\cline { 2 - 5 } & $\Delta, \%^{a}$ & $\sigma_{\Delta}, \%^{a}$ & $\Delta, \%^{a}$ & $\sigma_{\Delta}, \%^{a}$ \\
\hline $\mathrm{HTPB}+2 \% \mathrm{C}+10 \% \mathrm{ALEX}^{\mathrm{TM} b}$ & 24 & 20 & 34 & 21 \\
$\mathrm{HTPB}+2.8 \% \mathrm{MgB} 90(20 \% \mathrm{Mg})^{c} \mathrm{c}$ & 48 & 10 & 51 & 11 \\
$\mathrm{SW}^{d}$ & 335 & 160 & 325 & 157 \\
$\mathrm{SW}^{c}$ & 231 & 43 & 224 & 42 \\
$\mathrm{SW}^{e}$ & 216 & 62 & 209 & 60 \\
$\mathrm{SW}+2.8 \% \mathrm{MgB} 90(20 \% \mathrm{Mg})^{c}$ & 320 & 135 & 318 & 135 \\
\hline${ }^{a}$ Percentage evaluated with respect to HTPB baseline. & & \\
${ }^{b}$ Tested at 10 bar. & & & \\
${ }^{c}$ Tested at 13 bar. & & & \\
${ }^{d}$ Tested at 7 bar. & & & \\
${ }^{e}$ Tested at 16 bar. &
\end{tabular}

idizer mass flux of about $150 \mathrm{~kg} /\left(\mathrm{m}^{2} \cdot \mathrm{s}\right)$, regression rates of loaded and unloaded SW are roughly equivalent, while at $G_{\mathrm{Ox}}=100 \mathrm{~kg} /\left(\mathrm{m}^{2} \cdot \mathrm{s}\right)$, pure SW formulation exhibits an $r_{f}$ increase with respect to HTPB baseline of $+176 \%$, while MgB-loaded SW reaches $+144 \%$. An overview of the achieved average regression rate increases with respect to HTPB baseline for the tested fuel formulations is reported in Table 12.

\section{CONCLUDING REMARKS AND FUTURE DEVELOPMENTS}

HTPB- and SW-based solid fuels for hybrid propulsion were tested in a 2Dradial lab-scale burner under GOx. The regression rate data were obtained by an optical time-resolved technique and verified by the corresponding TOT measurements. Pure HTPB was taken as the reference baseline for the relative ballistic grading. Under the investigated operating conditions and over a pressure range of 7 to 16 bar, while HTPB exhibited an essential independence of $r_{f}$ on $p_{c}$, SW burning brought up some pressure dependence. Independence of $r_{f}$ on $p_{c}$ for HTPB is due to negligible changes in radiation heat transfer and chemical kinetics. Pressure effects on $r_{f}$ of SW are possibly related to entrainment effects. The considered metal-loaded formulations exhibit significant $r_{f}$ increases. With respect to HTPB baseline, considering $G_{\mathrm{Ox}}=300 \mathrm{~kg} /\left(\mathrm{m}^{2} \cdot \mathrm{s}\right)$, the MgB-loaded HTPB shows an $r_{f}$ enhancement of $56 \%$, while ALEX ${ }^{\mathrm{TM}}$ provides an $r_{f}$ increase of $35 \%$. Strong sensitivity to $G_{\mathrm{Ox}}$ reduces this performance enhancement as 


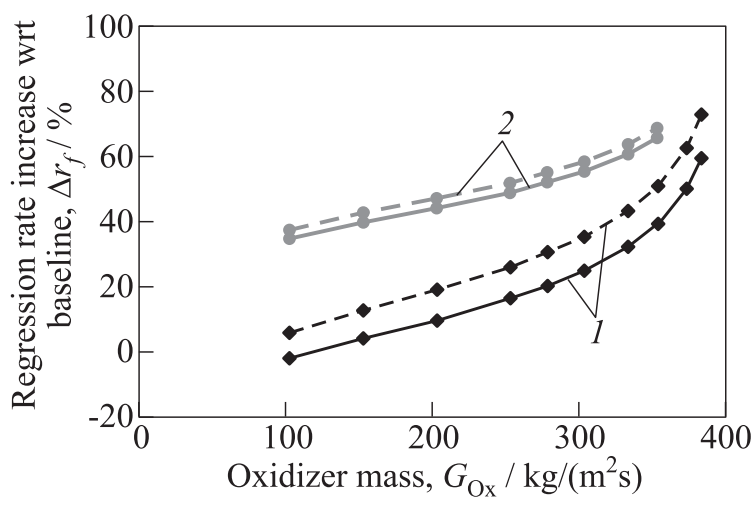

Figure 13 Instantaneous $r_{f}$ (solid curves) and $\dot{m}_{f}$ (dashed curves) percent variations with respect to HTPB baseline for HTPB metallized formulations over the whole investigated $G_{\mathrm{Ox}}$ range: $1-\mathrm{HTPB}+2 \% \mathrm{C}+10 \% \mathrm{ALEX}^{\mathrm{TM}}$; and $2-$ $\mathrm{HTPB}+2.8 \% \mathrm{MgB} 90(20 \% \mathrm{Mg}) ; \mathrm{MgB} 90(20 \% \mathrm{Mg})$ tested at $13 \mathrm{bar}$

combustion proceeds; nevertheless, the MgB-loaded fuel provides a significant $r_{f}$ enhancement of $33 \%$ at $100 \mathrm{~kg} /\left(\mathrm{m}^{2} \cdot \mathrm{s}\right)$ (Fig. 13). Solid paraffin wax loaded with MgB90 $(20 \% \mathrm{Mg})$ enables further increase in $r_{f}$ with respect to both unloaded SW and HTPB baseline formulations.

Based on the achieved results, the investigations about further regression rate increases using suitable variants of coated $\mathrm{ALEX}^{\mathrm{TM}} \mathrm{nAl}$ powders and $\mathrm{MgB}$ composite metals are recommended. Combining ALEX ${ }^{\mathrm{TM}}$ high density and $r_{f}$ enhancement at high $G_{\mathrm{Ox}}$ with $\mathrm{MgB}$, good overall performance appears as a promising direction in HRE development. While full exploitation of nanosized additives requires a proper dispersion down to the nanoscale, micronsized MgBbased additives do not require a dedicated manufacturing procedure.

\section{ACKNOWLEDGMENTS}

This work has partially been supported by CNES (Commande Nos. 4700024752/DLA090 and 4700028003/DLA094); and European Framework Program No. 7 (Theme 9: Space, program ORPHEE - Operative Research Program on Hybrid Engine in Europe, ORPHEE - WP 320 under Grant Agreement No. 218830).

The authors wish to acknowledge Advanced Powder Technology LLC (Tomsk, Russia) and Mach I (King of Prussia, Pennsylvania, USA) for the supply of energetic ingredients and valid support. 


\section{REFERENCES}

1. Altman, D., and A. Holzman. 2007. Overview and history of hybrid rocket propulsion. In: Fundamentals of hybrid rocket combustion and propulsion. Eds. M. J. Chiaverini, and K.K. Kuo. Progress in astronautics and aeronautics ser. AIAA. 218(Ch. 1):1-36.

2. DeLuca, L. T. 2009. Hybrid rocket engines. In: Energetic problems in aerospace propulsion. 3rd ed. Notes for Students, Premani, Pantigliate - Milano. Ch. 12: 192.

3. Kearney, D. A., K. F. Joiner, M.P. Gnau, and M. A. Casemore. 2007. Improving marketability of hybrid propulsion technology. AIAA Paper No. 2007-6144.

4. Marxman, G. A., and M. Gilbert. 1963. Turbulent boundary layer combustion in the hybrid rocket. 9th Symposium (International) on Combustion. New York: Academic Press, Inc. 371-83.

5. Marxman, G. A. 1967. Boundary layer combustion in propulsion. 11th Symposium (International) on Combustion Proceedings. Pittsburgh, Pennsylvania: The Combustion Institute. 269-89.

6. Marxman, G. A., and C.E. Wooldridge. 1968. Research on the combustion mechanism of hybrid rockets. In: Advances in tactical rocket propulsion. AGARD Conference Proceedings. Ed. S. S. Penner. 1:421-77.

7. Smoot, L. D., and C.F. Price. 1965. Regression rates of nonmetallized hybrid fuel systems. AIAA J. 3(8):1408-13.

8. George, P., S. Krishnan, P. M. Varkey, M. Ravindran, and L. Ramachandran. 2001. Fuel regression rate hydroxyl terminated polybutadiene/gaseous oxygen hybrid rocket motors. J. Propul. Power 17(1):35-42.

9. Houser, T. J., and M. V. Peck. 1964. Research in hybrid combustion. In: Heterogeneous combustion. Eds. H. G. Wolfhard, I. Glassman, and L. Green, Jr. Progress in astronautics and aeronautics ser. New York, NY, USA: Academic Press. 15:559-81.

10. Chiaverini, M. J. 2007. Review of solid fuel regression rate behavior in classical and nonclassical hybrid rocket motors. In: Fundamentals of hybrid rocket combustion and propulsion. Eds. M. J. Chiaverini, and K. K. Kuo. Progress in astronautics and aeronautics ser. AIAA. 218(Ch. 2):37-125.

11. Shin, H., C. Lee, and S. Y. Chang. 2005. The enhancement of regression rate of hybrid rocket fuel by various methods. AIAA Paper No. 2005-0359.

12. Lee, C., Y. Na, and G. Lee. 2005. The enhancement of regression rate of hybrid rocket fuel by helical grain configuration and swirl flow. AIAA Paper No. 2005-3906.

13. Frederick, R. A., J. J. Whitehead, L. R. Knox, and M. D. Moser. 2007. Regression rates study of mixed hybrid propellants. J. Propul. Power 23(1):175-80.

14. Risha, G. A., B. J. Evans, E. Boyer, and K. K. Kuo. 2007. Metals, energetic additives and special binders used in solid fuels for hybrid rockets. In: Fundamentals of hybrid rocket combustion and propulsion. Eds. M. J. Chiaverini, and K. K. Kuo. Progress in astronautics and aeronautics ser. AIAA. 218(Ch. 10):413-56.

15. Evans, B., E. Boyer, K. K. Kuo, G. Risha, and M. J. Chiaverini. 2009. Hybrid rocket investigations at Penn State University's High Pressure Combustion Laboratory: Overview and recent results. AIAA Paper No. 2009-5349. 
16. Karabeyoglu, M. A., D. Altman, and B. J. Cantwell. 2002. Combustion of liquefying hybrid propellants: Part 1. General theory. J. Propul. Power 18(3):610-20.

17. Karabeyoglu, M. A., and B. J. Cantwell. 2002. Combustion of liquefying hybrid propellants: Part 2. Stability of liquid films. J. Propul. Power 18(3):621-30.

18. Kim, S., J. Lee, H. Moon, H. Sung, J. Kim, and J. Cho. 2010. Effect of paraffinLDPE blended fuel in hybrid rocket motor. AIAA Paper No. 2010-7031.

19. Ivanov, Y.F., M. N. Osmonoliev, V.S. Sedoi, V. A. Arkhipov, S. S. Bondarchuk, A. B. Vorozhtsov, A. G. Korotkikh, and V.T. Kuznetsov. 2003. Productions of ultra-fine powders and their use in high energetic compositions. Propellants Explosives Pyrotechnics 28(6):319-33.

20. DeLuca, L. T. 2009. Metal combustion in aerospace propulsion. In: Energetic problems in aerospace propulsion. 3rd ed. Notes for Students, Premani, Pantigliate Milano. Ch. 6: 1-38.

21. Dikici, B., S. W. Dean, M. L. Pantoya, V. I. Levitas, and R. J. Jouet. 2009. Influence of aluminum passivation on the reaction mechanism: Flame propagation studies. Energy Fuels 23:4231-35.

22. DeLuca, L.T., L. Galfetti, F. Bosisio, H. Raina, A. Colombo, and G. Colombo. 2006. A hybrid microcombustor for regression rate measurements. 57th Astronautical Congress (International) (IAC) Proceedings. IAC-06-C4.2.01.

23. DeLuca, L. T., L. Galfetti, G. Colombo, F. Maggi, A. Bandera, M. Boiocchi, G. Gariani, L. Merotto, C. Paravan, and A. Reina. 2011. Time-resolved burning of solid fuels for hybrid rocket propulsion. In: Progress in propulsion physics. Eds. L. T. DeLuca, Ch. Bonnal, O. Haidn, and S. M. Frolov. EUCASS advances in aerospace sciences book ser. Moscow: TORUS PRESS. 2:405-26.

24. Arisawa, H., and T. B. Brill. 1996. Flash pyrolysis of hydroxyl terminated polybutadiene (HTPB) I: Analysis and implications of the gaseous products. Combust. Flame 106:131-43.

25. Arisawa, H., and T. B. Brill. 1996. Flash pyrolysis of hydroxyl terminated polybutadiene (HTPB) II: Implications of the kinetics to combustion of organic polymers. Combust. Flame 106:144-54.

26. Gromov, A. A., A. Ilyin, V. An, F. Faubert, C. de Izarra, A. Espagnacq, and L. Brunet. 2002. Characterization of aluminum powders: I. Parameters of reactivity of aluminum powders. Propellants Explosives Pyrotechnics 27(6):361-64.

27. Gromov, A. A., A. Ilyin, U. Forter-Barth, and U. Teipel. 2006. Characterization of aluminum powders: II. Aluminum nanopowders passivated by non-inert coatings. Propellants Explosives Pyrotechnics 31(5):401-9.

28. Chen, L., W. L. Song, J. Li, L. Wang, and C. S. Xie. 2009. Effect of heating rates on TG-DTA results of aluminum nanopowders prepared by laser heating evaporation. J. Thermal Anal. Calorimetry 96(1):141-45.

29. Reina, A., G. Colombo, L. T. DeLuca, F. Maggi, I. Lesniak, D. B. Lempert, and G. B. Manelis. 2010. Magnesium and aluminum ignition in $\mathrm{CO}_{2}$ atmosphere. Aerotecnica Missili e Spazio 8(1):14-23.

30. Ivanov, Y.F., M. N. Osmonoliev, V.S. Sedoi, V.A. Arkhipov, S.S. Bondarchuk, A. B. Vorozhtsov, A. G. Korotkikh, and V.T. Kuznetsov. 2003. Productions of 
ultra-fine powders and their use in high energetic compositions. Propellants Explosives Pyrotechnics 28(6):319-33.

31. Nielsen, L.E. 1974. Particulate filled polymers. In: Mechanical properties of polymers and composites. Vol. 2. New York: Marcel Dekker Inc. 2(Ch. 7):379-441.

32. Ohlemiller, T. J., and M. Summerfield. 1968. A critical analysis of arc image ignition of solid propellants. AIAA J. 6(5):878-86.

33. Incropera, F. P., and D. P. DeWitt. 1990. Fundamentals of heat and mass transfer. 3rd ed. New York: Wiley. 515 p.

34. DeLuca, L. T., C. Paravan, A. Reina, E. Marchesi, F. Maggi, A. Bandera, G. Colombo, and B. M. Kosowski. 2010. Aggregation and incipient agglomeration in metallized solid propellants and solid fuels for rocket propulsion. AIAA Paper No. 2010-6752. 